\title{
A CULTURA DE ESTUPRO: $O$ ARCABOUÇO DA DESIGUALDADE, DA TOLERẨNCIA À VIOLÊNCIA, DA OBJETIFICAÇÃO DA MULHER E DA CULPABILIZAÇÃO DA VÍTIMA
}

\section{A CULTURE OF RAPE: A SYSTEM OF INEQUALITY, VIOLENCE TOLERANCE, WOMEN OBJECTIFICATION AND VICTIM BLAMING}

\author{
Clariana Leal Sommacal ${ }^{1}$ \\ Priscila de Azambuja Tagliari ${ }^{2}$
}

Resumo: $O$ presente artigo busca analisar a cultura de estupro e as suas características sob a perspectiva do sistema de gênero, observando as situações que ensejam a vigência da concepção discriminatória da mulher. Tendo como base a correlação entre o gênero, o poder, a dominação e as mais variadas formas de violência praticadas contra o sexo feminino, com especial enfoque no crime de estupro, analisar-se-á as circunstâncias concernentes à cultura do estupro, as quais se materializam na normalização da violência, na objetificação da mulher e na culpabilização da vítima; características essas que, além de promover o culto do crime em comento, ensejama permanência da mulher em um patamar inferior, desigual e adstrita às condutas morais socialmente esperadas pelo sexo feminino.

Palavras-chave: Gênero. Violência. Mulher. Cultura do estupro.

Abstract: The article aims to perform a scrutiny about the culture of rape e its characteristics under the perspective of the gender system, observing the facts that have stood out a conception of prejudice upon women. Based on the correlation among gender, power, domination, and the wide variety of forms of violence practiced against the female gender, presenting an especial emphasis on the crime of rape, there will be a throughout scrutiny about the circumstances that have identified among society a culture of rape, which has materialized itself when the type

1 Bacharela em Direito pela Universidade do Sul de Santa Catarina. Empregada no escritório Brasil \& Brasil Advogados. E-mail: clsommacal@gmail.com.

2 Especialista em Ciências Penais pela Unisul e professora da Unisul. E-mail: priscilatagliari@hotmail.com. 
of violence became something seen as normal among society, when women started to be treated as an object, and when society started to blame the victim in the case of violence; those are characteristics that, apart from promot- ing a cult in favor of the crime, have deemed women to an inferior status, unequal and limited to the moral conducts socially expected from women..

Keywords: Gender. Violence. Women. Culture of Rape.

\section{INTRODUÇÃO}

O presente artigo versa sobre a cultura de estupro e tem como objetivo demonstrar as principais características que sustentam a vigência dos comportamentos e costumes discriminatórios da mulher e também do culto à violência e ao estupro. Primeiramente, far-se-á uma ponderação acerca dos mecanismos de dominação patriarcal, em especial o sistema de gênero, o poder e a violência, analisando-os de maneira relacional e interligada.

Após a conceituação inicial, observar-se-á a definição do estupro e a sua origem, analisando o momento histórico em que as relações sexuais forçadas passaram a ser praticadas e qual o objetivo da perpetração do delito, examinando o estupro como violência e não somente como um mero comportamento sexual. Será esclarecido, ademais, o motivo pelo qual o estupro tardou a ser efetivamente estudado.

Por fim, analisar-se-á com maior especificidade a cultura de estupro e as bases que a amparam, entre elas a normalização da violência contra a mulher, a objetificação e sexualização do corpo feminino e a culpabilização da vítima de estupro.

\section{GÊNERO, PODER E VIOLÊNCIA}

Considerando que a consolidação e a permanência da cultura do estupro no seio social diz respeito ao desdobramento do gênero, do poder e da violência, faz mister expor uma breve conceituação de cada um desses pilares. Iniciando-se com o gênero, pode-se falar em um sistema criado culturalmente, compreendi- 
do como uma construção social da identidade sexual dos seres humanos. Muito embora tenha se desenvolvido de maneira maleável durante o deslinde histórico, com ele estratificou-se uma hierarquia: o gênero masculino em patamar superior e o feminino em posição de sujeição (SILVA, 2010, p. 49).

Visando manter o molde hierárquico das premissas de gênero, o poder e a violência passam a ser articulados, fazendo com que tais sustentáculos se desenvolvam conjuntamente. Deste modo, o poder é ratificado por meio da dominação e da violência, de modo que esta se afigura como "[...] um mecanismo necessário à perpetuação do poder masculino" sobre as mulheres (SANTOS, 2008, p. 46).

Por ser a violência uma maneira de dominação patriarcal histórica, se encontra ela "[...] impregnada de profundos conteúdos inconscientes" (DIAS, 2010, p. 3), presente em diversas situações cotidianas taxadas como usuais, como pela discriminação da mulher, pela linguagem ofensiva, pelas piadas machistas, pelo estereótipo de corpo, pela obstrução da liberdade sexual, pela intimidação, pelo assédio, pelo abuso, pelo estupro e pela morte (SANTOS, 2008, p. 23).

Nesse ponto se observa o aparecimento do poder simbólico, no qual as normas da sociedade são consideradas naturais e, assim, inquestionáveis, legitimando a sua vigência e aderência pelos cidadãos que nela se integram. De acordo com Bourdieu "[...] o poder simbólico viabiliza e legitima o exercício de outras formas de poder por meio do obscurecimento da realidade" (2000 apud BICALHO; DE PAULA, 2009, p. 3). Não é outro o caso do estupro, um comportamento sexual forçado e muitas vezes justificado, naturalizado e ofuscado a serviço do machismo, da opressão, da misoginia e da violência.

\subsection{O estupro}

Insta salientar, a priori, que muitos autores se demonstra- 
ram relutantes em escrever sobre o estupro, como relatou $\mathrm{Su}-$ san Brownmiller, alegando que nem Sigmund Freud, pai da psicanálise, o qual deu origem ao conceito da primazia do pênis, e muito menos Karl Marx e Friedrich Engels abordaram em suas teorias socialistas o crime de estupro; e o que "Os mestres ignoraram, os discípulos tenderam a ignorar também." (BROWNMILLER, 1993, p. 11-12, tradução nossa). Por derradeiro, em uma sociedade controlada por uma irmandade de homens, nada mais conveniente que o estupro permanecesse abstruso e silenciado, sem abordar a concepção de que o órgão genital daqueles pode ser utilizado como uma arma contra a população feminina.

Muito embora o sexo no mundo animal ocorra somente durante o ciclo menstrual da fêmea, para os seres humanos esse independe de uma situação biológica e tampouco da receptividade da mulher, mas tão somente da ereção do pênis do homem. Em razão disso, na pré-história, assim que os homens o descobriram passaram a utilizar esse recurso para proceder aos estupros, de modo que os primeiros vínculos sexuais teriam ocorrido de maneira forçada; o que, somente muito depois, passou a ser considerado crime (BROWNMILLER, 1993, p. 13-14, tradução nossa). É importante sobrelevar que a atualidade em nada foi modificada, onde $47 \%$ das mulheres tiveram sua primeira relação sexual não consentida (SMINKLEY, 2016, tradução nossa).

Conforme os estudos de Santos, o emprego da força nas relações humanas visa ratificar a sobreposição do homem e a sujeição da mulher, diante da concepção enraizada de que o patriarca tem direito sobre o corpo daquela. A intenção ao estuprar uma mulher é, portanto, a imposição de poder e controle sobre o corpo da vítima, o qual conjectura como um objeto de dominação (SANTOS, 2008, p. 61-64). Não obstante, a função do estupro tem como premissa a intimidação, 
objetivando perpetrar um estado de medo constante em todas as mulheres, conforme discorre Brownmiller:

O estupro tornou-se não só uma prerrogativa masculina, mas uma arma básica de força do homem contra as mulheres, o principal agente de sua vontade é o medo delas. A entrada forçada em seu corpo, apesar de seus protestos físicos e luta, tornou-se o veículo de sua conquista vitoriosa sobre o seu ser, o teste final de sua força superior, o triunfo de sua masculinidade (1993, p. 14, tradução nossa).

Pelo exposto, o estupro nada tem a ver com satisfação da lascívia ou obtenção de prazer, considerando que o sexo "[...] é um meio pela qual a violência ocorre" (LANA et al., 2016, p. 175). Outrossim, o estupro é um ato ou "comportamento sexual a serviços de necessidades não sexuais", quais sejam a "agressão, controle e domínio", como observam Kolodny, Masters e Johnson:

Quanto à etiologia do estupro, sabe-se, hoje, na esteira da primeira argumentação, que não se trata de conduta voltada, prioritariamente, para a satisfação do prazer sexual (lascívia desenfreada), como também preconiza o discurso criminológico e jurídico-penal oficial e o senso comum [...] a maioria dos estupros ocorrem dentro de um contexto de violência física em vez de paixão sexual ou como meio para a satisfação sexual (KOLODNY; MASTERS; JOHNSON, 1982, p. 430-431 apud ANDRADE, 2005, p. 96).

Ineficaz, em razão disso, a punição com a castração química do condenado por estupro, como pretende o Projeto de Lei n 5398/13, pois em nada resolveria o desejo de domínio masculino e permaneceria "[...] acentuando o encontro sexual e o coito vaginal antes que a violência" (PROJETO..., 2016; ANDRADE, 2005, p. 97). Ineficaz, ademais, a aplicação rigorosa da Lei, que não modifica a concepção majoritária dos homens, cuja moral entende a mulher como sua propriedade; haja vista que o problema se encontra implantado na cabeça dos homens, e não em seu órgão genital. 
Importante acentuar que o crime de estupro está previsto atualmente no art. 213 do Código Penal, configurando "Constranger alguém, mediante violência ou grave ameaça, a ter conjunção carnal, praticar ou permitir que se pratique outro ato libidinoso.", tendo como pena de reclusão de 6 à 10 anos (BRASIL, 2009).

\section{A CULTURA DE ESTUPRO}

Em se tratando do estupro como um fenômeno estrutural presente nas relações sociais, pode ser esse concebido como uma violência controladora emanada historicamente nos mais diversos ambientes, tanto dentro da família, como na Igreja, no trabalho e no espaço público (ANDRADE, 2005, p. 96). Por ser um crime recorrentemente praticado, estima-se que $527 \mathrm{mil}$ pessoas são estupradas por ano no Brasil, em um cenário de que a cada 11 minutos uma dessas é estuprada; e a mulher, mesmo figurando como metade da população, é o alvo majoritário da execução do delito, representando 89\% das vítimas (INSTITUTO DE PESQUISA ECONÔMICA APLICADA, 2014, p. 26; BUENO, 2015, p. 116).

Antes de desbravar a cultura de estupro, insta abordar o conceito de cultura em si, que segundo Buchwald, Fletcher e Roth, diz respeito ao modo "[...] no qual uma sociedade opera formalmente e informalmente, com base em atitudes, crenças, costumes e rituais que seus membros sancionam como aceitável e normal" (2005 apud FLETCHER, 2010, p. 1, tradução nossa). Dessarte, a herança cultural é o prisma da reprodução das "anacrônicas tendências", que ao minimizar as consequências do conflito, utiliza-se da prevalência do costume para dar solidez a uma realidade desponderada (DIAS, 2010, p. 4).

Nesse norte, a terminologia cultura do estupro advém do termo em inglês Rape Culture, introduzido pelas ativistas feministas estadunidenses nos anos 70, que diz respeito a uma 
norma incutida no seio social que por meio de um complexo de crenças, incentiva a prática do crime, tolera a violência contra a mulher e atribui a culpa às suas respectivas vítimas (WOMENS AGAINST VIOLENCE AGAINST WOMEN, 2016, tradução nossa; FLETCHER, 2010, p. 1, tradução nossa).

Por se tratar de um crime estruturado na sociedade, a cultura de estupro opera de maneira sutil e imperceptível aos olhos dos cidadãos, que já normalizam a violência; configura, assim, uma forma de violência simbólica, que muito embora seja mascarada, possui efeitos reais e materiais na sociedade e principalmente nas vítimas (LANA et al., 2016, p. 164). Nesse ponto, a cultura do estupro perdura no manto das culturas " [...] como um mecanismo de controle historicamente frequente, mas amplamente ignorado, mantido por instituições patriarcais e relações sociais que reforçam a dominação masculina e a subjugação feminina" (VITTO, GIL e SHORT, 2009 apud BROWNMILLER, 1975, p. 256 apud SILVA, 2014, p. 133).

Com efeito, esse fenômeno coexiste dentro de um paradoxo social de modo que, em que pese seja tipificado como delito e considerado crime hediondo, quando perpetrado, o impulso da maioria dos cidadãos é de justificar a ocorrência por algum fator ligado a vítima ou ao agressor (LANA et al., 2016, p. 165); este que penetrou à força por um mero descontrole psicológico, e aquela que atuou em desconformidade com as normas sociais vigentes.

Assim sendo, criou-se a concepção de que esse crime só seria cometido por estranhos; um estereótipo de agressor como um ser anormal, desconhecido ou doente, cuja lascívia não pode controlar (ANDRADE, 2005, p. 97). Entretanto, estuprador não é doente, mas sim, um patriarca saudável e frequentemente ligado à vida pessoal da vítima, como concluiu um estudo do Instituto de Pesquisa Econômica Aplicada (2014, p. 9), revelando que $70 \%$ dos estupros são praticados por pessoas 
presentes no ciclo de amizade da vítima, sendo executados por conhecidos, amigos, namorados ou parentes.

O âmbito familiar, dessa forma, é o local com maior incidência do delito e também o "[...] palco das maiores e mais volumosas agressões" (DIAS, 2010, p. 2). O estupro marital, por exemplo, já foi admitido no ordenamento jurídico brasileiro, mas em que pese afastada essa hipótese, a população permanece vendo o sexo como um dever matrimonial, por vezes exclusivo à atuação do homem e a sujeição da mulher; deste fato surge o ditado popular de que após o sexo "o homem comeu a mulher", impondo a esta o status passivo da relação sexual, como se o seu corpo o pertencesse após o ato, como se fosse de fato um alimento a ser ingerido ou um objeto a ser consumido.

Em face da relutância de se falar em estupro, as pessoas tendem a confundir o seu significado, de modo que os homens desconhecem o consentimento e confundem a configuração do crime, acreditando haver uma diferença entre forçar uma mulher a fazer sexo e a estuprar. Uma pesquisa realizada confirmou essa situação, na qual os entrevistados confessaram que, em não havendo consequências, $31,7 \%$ forçariam uma mulher a manter relação sexual, ao passo que somente $13,6 \%$ expressamente estuprariam uma mulher (EDWARD, BRADSHAW, HINSZ, 2014, p. 190, tradução nossa). Sem embargo, faz-se mister esclarecer que obrigar uma mulher a transar, ter uma relação sexual não consentida ou constranger uma mulher a fazer sexo é equivalente a estuprar.

A cultura de estupro é fomentada pelos comportamentos machistas naturalizados e incentivada pela etiqueta comportamental e corporal imposta às mulheres, concedendo a liberdade de ofensa aos homens e, em contrapartida, a obstrução dos direitos da mulher. No afã de reforçar esses paradigmas, é cediço que aquele que promove a discriminação e o abuso procure deslegi- 
timar a violência de alguma maneira, alegando que se trata de uma invenção feminista; que "mulher feia" não deveria reclamar de ser estuprada, como afirmou Rafael Bastos (R7 ENTRETENIMENTO, 2016); que afirma ser um gênio aquele que induz a ingestão de bebidas alcóolicas para possibilitar o sexo, como afirmou Danilo Gentili (LIBERO, 2016); ou que anuncia que "não estupraria uma parlamentar porque ela não merecia", como o fez o deputado Jair Bolsonaro para a parlamentar Maria do Rosário (ORDEM DOS ADVOGADOS DO BRASIL, 2016). Ressalta-se que muito embora atos como esses sejam criticados, há grande parcela da população que os defende e os glorifica, destacando a mentalidade discriminatória ainda presente.

Vigora na sociedade um manto conservador e machista que além de resistir em aceitar a existência de uma cultura de estupro, faz notória displicência aos direitos da mulher, compactuando, assim, com a vigência do culto aos assédios sexuais e com o prosseguimento da opressão da mulher.

\subsection{A normalização da violência e a objetificação da mulher}

A normalização da violência encontra-se inserta na cultura do estupro e consiste em taxar como usual e comum as condutas sexuais afrontosas à dignidade da mulher, sob a perspectiva de que esta pertence ao homem, assim como seu corpo, como reflete Fletcher:

Dada esta tendência global, mulheres e homens aceitam a violência sexual como normal e interminável. Em sua aceitação, eles tacitamente aprovam a noção de que os corpos das mulheres e das crianças pertencem aos homens para que os tratem de acordo com sua vontade. Como resultado, a instituição injusta do patriarcado que tolera e sustenta uma cultura de estupro, que desumaniza mulheres e meninas, tende a não ser examinada e contestada (2010, p. 1, tradução nossa).

$\mathrm{O}$ contexto da desigualdade de gênero, da tolerância à 
violência e da obstrução da liberdade sexual da mulher, é essencial para a permanência do patriarcado no poder e para a vigência da cultura de estupro. Nesse diapasão, promove-se uma inversão de valores, contemplando a violência como sexy e a sexualidade da mulher, por sua vez, como ultrajante (FLETCHER, 2010, p. 1, tradução nossa). Ao passo que o natural desenvolvimento do corpo feminino é repreendido, assim como a sexualidade da mulher; a dos homens, por outro lado, é amplamente incentivada por ser considerada inerente a sua característica dominadora; exclusiva, pois, do sexo masculino (FOUCAULT, 1987 apud SANTOS, 2008, p. 166).

Em face disso, a população feminina é dividida em dois polos: as santas, dignas de respeito, ou as prostitutas, desvirtuadas, indecentes ou promíscuas, que possuem postura sexual ativa (LANA et al., 2016, p. 78-79). No entanto, mesmo que tenha sido a sexualidade privatizada, as mulheres são representadas como seres sexualizados em propagandas midiáticas, associadas a objetos, cujo enfoque primordial são os atributos; fragmentando, assim, a sua integridade (CRUZ, 2008, p. 7).

Representam-na e a resumem a um objeto, haja vista que o seu destino é o consumo masculino, que idealiza uma mulher perfeita, sem ranhuras ou avarias. Esse fenômeno é denominado objetificação da mulher, outra característica predominante na cultura do estupro; taxando-a como objeto sexual e glamourizando a violência contra ela praticada, senão veja-se:

Cultura do estupro é um ambiente em que estupro é prevalente e que violência sexual é normalizada e dispensada na mídia e na cultura popular. A cultura do estupro é perpetuada através do uso de linguagem misógina, a objetificação dos corpos das mulheres e a glamourização da violência sexual, criando uma sociedade que ignora os direitos das mulheres e segurança (WOMEN'S CENTER OF MARSHALL UNIVERSITY, 2016, tradução nossa).

A objetificação pode ser observada nas seguintes situações: 
fazer analogia da mulher a um objeto, o qual não possui escolha ou voz e não é tratada como sujeito de direitos; a utilização de plástica ou retoque, construindo um modelo que foge do alcance ou da realidade humana; e a redução da mulher a somente uma parte provocativa do corpo (WHAT..., 2016, tradução nossa). Propagandas com esse teor não são alvo de repúdio, mas ao contrário, promovem o aumento das vendas e o lucro das empresas, enfatizando, ainda mais, a realidade destorcida na qual se encontra a sociedade.

A glamourização da violência e a objetificação da mulher se encontram para além das campanhas de moda, presentes também na mídia, em filmes, em jogos e na pornografia (SOUTHERN CONNECTICUT STATE UNIVERSITY, 2016, tradução nossa). É o que se viu presente na revelação de Alexandre Frota em rede nacional, que ao confessar ter estuprado uma Mãe-de-Santo, foi recepcionado pela plateia com aplausos e risos excessivos (PRAGMATISMO POLÍTICO, 2016b). Acentua-se que esse ex-ator, mesmo após admitir tal prática delitiva, foi recebido pelo Ministro da Educação para implementar as suas sugestões à educação do país (SAKAMOTO, 2016).

\subsection{A culpabilização da vítima de estupro}

A culpabilização da vítima advém do termo em inglês VictimBlaming, criado em 1971 por William Ryan que, inicialmente, contemplou o estudo das minorias étnicas dos Estados Unidos por meio da atribuição, pela classe média, da culpa aos

pobres por sua pobreza. A terminologia foi também aplicada às vítimas de estupro, a qual objetiva justificar a motivação do crime por análise de sua conduta, evitando a aplicação da pena e mantendo a reincidência e invisibilidade do crime na sociedade (SCHOELLKOPF, 2012, p. 2-3, tradução nossa).

A culpabilização da vítima de estupro pode ser compreendida como um fenômeno derivado das relações de gênero desi- 
guais e incutida na cultura de estupro, que culmina na atribuição da responsabilidade pelo crime à mulher (SEMÍRAMIS, 2016). Assim, coloca-se em pauta o cotejo da vítima para que, ao invés de considerar o criminoso como culpado, indagar-se profundamente a vida da mulher, visando à exclusão de culpabilidade daquele.

Pretende-se, na verdade, o adestramento da sexualidade feminina, vigiando profundamente e punindo com comentários coniventes com a conduta criminosa, abarcando na tolerância social do respectivo delito, como reflete Lima:

A investigação social sobre a contribuição da vítima para a ocorrência do crime está edificada no controle da sexualidade feminina. Na verdade, todos os modelos de conduta apontados como tipicamente femininos são explicados culturalmente como a melhor forma de evitar maiores males. Para as massas, se a mulher é cuidadosa e não se desvia das regras comportamentais do seio social, certamente terá menores chances de se tornas vítima de violência sexual. Implica dizer que, para o senso comum, normalmente a mulher só é estuprada se der algum motivo, o qual geralmente está imbricado com sua moral sexual (LIMA, 2012, 17).

A sexualidade da mulher, como visto, é sempre alvo de severa análise, tanto pela sociedade, como pelos ordenadores do direito, que tendem nos julgamentos de crimes sexuais a desviar da conduta delitiva e abordar especificamente a sexualidade da mulher como causa do crime; ou, de outro modo, relativizar os depoimentos quando feitos por mulheres com conduta sexual ativa ou diversa daquela esperada pelo sexo feminino (SANTOS, 2008, p. 167-169).

Insta inferir que o misticismo bíblico muito influencia essa situação ao associar a mulher ao vício e à perversão, de modo que o homem, desta maneira, é descontrolado pela tentação proposta, seja por um suposto excesso de testosterona ou por seu impulso natural. Nessa lógica, "[...] o corpo das mulheres 
potencializa a virilidade masculina, que na cultura de estupro se concretiza num ato brutal." (NASCIMENTO, 2016), como se depreende do seguinte fragmento:

[...] A mulher, chama voraz, loucura extrema, inimiga íntima, aprende e ensina tudo o que pode prejudicar. A mulher, vil fórum, coisa pública, nascida para enganar, pensa ter triunfado quando pode ser culpada. Consumindo tudo no vício, é consumida por todos; predadora dos homens, torna-se ela própria a presa> [...]. (DALARUN, 1993, p. 38).

Destarte, sendo o corpo da mulher ligado aos pecados, será essa merecedora de punição quando do desvio da conduta moral socialmente esperada do sexo feminino; em fazendo ela jus à violência, incorre-se na normalização da agressão, justificando-a para assegurar que a brutalidade é de fato admissível no presente cenário. Promove-se, com isso, uma inversão do ônus da prova que resulta na atribuição da responsabilidade do crime à mulher (ANDRADE, 1997 apud ROST, VIEIRA, 2015, p. 269).

De acordo com o Canadian Resource Centre For Victims of Crime (2009, p. 3, tradução nossa), existem dois tipos de atribuição de culpa; a interna, que consiste no reconhecimento que a causa do crime se deu em razão da característica pessoal da vítima; e a externa, que reconhece que o ambiente e demais circunstâncias motivaram a prática criminosa. Denota-se que ambas as formas de atribuição da culpa consistem em afastar o criminoso da persecução penal, desviando-se a questio do seu devido enfoque.

As perscrutações exercidas sobre a mulher, vítima de estupro pareiam, de uma maneira geral, sobre a roupa que estava vestindo, o local que se encontrava e em qual horário, o nível de álcool em seu sangue, se o sujeito ativo era conhecido, e sobre o seu desempenho sexual, como se pode ver do seguinte trecho:

[...] Teria a mulher-vítima se comportado segundo razoáveis padrões decência? Teria demonstrado, nas circunstâncias, suficiente pundonor? Teria a sua conduta se amoldado 
aos padrões de moralidade pública que a sociedade espera? Não teria a conduta da vítima, de algum modo, ferido o sentimento comum? Ter-se-ia conduzido a vítima de acordo com os padrões derivados do que se entende por bons costumes? [...] a vítima agiu de acordo com os princípios éticos? A vítima conformou-se à moral sexual de seu tempo e do espaço? A vítima apresentou comportamento uniforme? A vítima, antes do fato, era respeitada pela generalidade das pessoas honestas? A vítima, por outro lado, sofreu algum tipo de violência? A vítima resistiu aos propósitos do agente, ou deles dissentiu comprovadamente? [...] se coteja a vítima, ou suposta vítima, com os conceitos de pudor, moral, honra, decência, honestidade, bons costumes, moralidade pública, e outros, a partir dos fatos de que ela haja participado, para se aferir o grau, a qualidade e a profundidade dessa participação, a fim de desses indicativos extrair a verdadeira culpabilidade do acusado e a maior ou menor responsabilidade da vítima pela deflagração do evento tido por criminoso, [...] (SOUZA, 1998, p. 62-66).

O pensamento difundido que culpabiliza a vítima está presente nos mais diversos ambientes, tanto o é que o autor acima é, in casu, magistrado, o qual firmou seus estudos com base no Instituto da Vitimologia. A tese vitimológica objetiva estudar o papel da vítima nas consequências da atividade delitiva (GRECO, 2004, p. 13), mas sabe-se que, no entanto, tem como base os estereótipos de gênero, dando a vítima tratamento igualitário ao agressor; e por essas razões, entende-se que não se pode analisar o estupro com base nessas premissas (HULSMAN, BERNAT DE CELIS, 1993, p. 83 apud ANDRADE, 2005, p. 82).

Controlando a moralidade e sexualidade feminina a população, em geral, não admite que seja a mulher um sujeito livre como qualquer outro, mantendo-a em um cerco invisível e infeliz, sob assertivas patriarcais e discriminatórias. Uma pesquisa realizada pelo Instituto Avon e pelo Data Popular concluiu que $85 \%$ dos homens julgam inaceitável a embriaguez de uma mulher (POSADA, 2013, p. 25); e em contrapartida, outra pesquisa 
feita pelos mesmos autores concluiu que $27 \%$ dos entrevistados alegaram não considerar violência abusar de mulheres em estado alcoólico (INSTITUTO AVON, 2015, p. 5-6).

Como visto, a violência contra a mulher é admitida em determinadas situações, sendo legitimada pela suposta conduta inadequada da vítima (NASCIMENTO, 2013, p. 26). Outro dado revelador do primeiro estudo foi que $46 \%$ julgam inaceitável a utilização de roupas justas ou decotadas por mulheres (POSADA, 2013, p. 25), ao passo que $26 \%$ dos entrevistados acreditam que "Mulheres que usam roupa que mostra o corpo merecem ser atacadas"; ademais, 58\% concorda que "Se as mulheres soubessem como se comportar, haveriam menos estupros" (INSTITUTO DE PESQUISA ECONÔMICA APLICADA, 2014b, p. 22).

Diante os dados acima se denota que a concepção majoritária busca limitar a mulher, a qual não pode beber e muito menos vestir-se como julgar adequado, sem ser alvo de imputação de culpa ou de discriminação. Culpabiliza-se, na verdade, o exercício de sua liberdade, que notoriamente ainda não é legítimo ou sequer integral.

Pondera-se que não somente pelo estupro, mas por outras situações cotidianas a mulher tende a receber a culpa: pelo insucesso matrimonial, pela infidelidade conjugal e, até mesmo, pela inexitosa relação sexual. No entanto, nenhuma situação presta compromisso com a origem do problema, ou por quem o praticou; voltam-se os olhares para a vida particular da vítima, acreditando-se ser ela a razão de todos os problemas ocorridos na sociedade.

Por ser um entendimento difundido no seio social, as autoridades policiais, as delegacias de polícia, o judiciário e todo o Sistema de Justiça Criminal também seguem a mesma linha de pensamento, atuando nas conformidades da Lei patriarcal (LANA et al., 2016, p. 174); encontram-se, em razão disso, 
despreparados para lidar com crimes sexuais, como relata Vera Regina Pereira de Andrade:

[...] num sentido forte, o SJC (salvo situações contingentes e excepcionais) não apenas é um meio ineficaz para a proteção das mulheres contra a violência (particularmente da violência sexual, que é o tema da pesquisa) como também duplica a violência exercida contra elas e as divide, sendo uma estratégia excludente que afeta a própria unidade (já complexa) do movimento feminista (ANDRADE, 2005, p. 75).

Como visto, a violência é duplicada, sendo a vítima além de violentada na ocorrência do estupro, posteriormente quando do relato às autoridades competentes, que agem, desta maneira, em conluio para com o agressor e para com a conduta criminosa (LIMA, 2012, p. 20). Colaboram, assim, para o silêncio das vítimas e também com a porcentagem de menos de $10 \%$ dos ocorridos são reportados à polícia (FAÚNDES et al., 1998 apud INSTITUTO DE PESQUISA ECONÔMICA APLICADA, 2014, p. 6).

Não bastasse isso, exigem da vítima alto grau de resistência para esgrimir-se do ato violento, não bastando a sua simples negativa, como se depreende das seguintes decisões proferidas pelo Tribunal de Justiça de São Paulo:

Estupro é a posse por força ou grave ameaça, supondo dissenso sincero e positivo da vítima, não bastando recusa meramente verbal ou oposição passiva e inerte (TJSP, RT 488/336) [...] A oposição da vítima deve ser sincera e positiva, manifestando-se por inequívoca resistência (TJ/SP, RT 533/326). Não basta a oposição meramente simbólica (TJSP, RT 535/287), por simples gritos (TJSP, RT 429/400) (DELMANTO et al., 2010, p. 695).

Muito embora a palavra da vítima goze de presunção de veracidade, conforme entendimento consolidado pelo Supremo Tribunal de Justiça, as assertivas deverão coincidir com as provas juntadas aos autos, local em que se assenta o problema; os demais elementos probatórios são, na verdade, a análise da 
conduta moral e sexual da vítima, culminando "[...] por ver-se ela própria 'julgada' (pela visão masculina da lei, da polícia, da Justiça)" (ANDRADE, 2005, p. 93; LANA et al., 2016, p. 173). Nessa estirpe, Izumino afirma que o judiciário "[...] tem se apresentado muito mais enquanto instância reprodutora de desigualdades", negligenciando a segurança jurídica e a proteção da mulher, levando, em razão disso, à ineficácia da medida jurisdicional (IZUMINO, 1989 PIMENTEL, SCHRITZMEYER E PANDJIARJIAN, 1998).

A atribuição da responsabilidade pelo Sistema de Justiça Criminal pode se ver materializada em um caso ocorrido na cidade do Rio de Janeiro, no Brasil, em 2016, onde uma menina menor de 16 anos foi alvo de um estupro coletivo. Os agressores filmaram a vítima desacordada e ferida, afirmando serem eles os respectivos autores do crime e, mesmo após a sua confissão e diante de provas robustas, o Delegado de Polícia responsável liberou os acusados afirmando "A gente está investigando se houve consentimento dela, se ela estava dopada e se realmente os fatos aconteceram", questionando, ainda, se a vítima tinha por hábito a prática de sexo grupal (MARREIRO, 2016).

Nas palavras da vítima "O delegado queria me botar a culpa de todas as formas", e, em razão disso, veio a ser ele afastado do caso, passando a ser conduzido por uma delegada mulher (BIANCHI, 2016). No entanto, não somente o delegado buscou responsabilizá-la, mas também demais sargentos, soldados da PM, cabos, majores e civis que expuseram a vítima nas redes sociais; ridicularizaram-na por ter ingerido bebida, usar roupas curtas, relacionar-se com pessoas ligadas ao tráfico e por frequentar bailes funk (PONTE JORNALISMO, 2016). Condições essas que sob nenhuma hipótese justificam a violência contra ela praticada.

Dada à repercussão internacional a que tomou o crime, a Organização das Nações Unidas Mulheres do Brasil exigiu do go- 
verno brasileiro providências ao caso (GASMAN, 2016). Pressionado, o Senado Federal aprovou o Projeto de Lei n. 618/2015, que tipifica o estupro coletivo e prevê o aumento de pena à um terço, levando à punição para além de 13 anos. Prevê, ainda, uma maior punição pela divulgação de imagens do crime, que até então era considerado crime de injúria (PROJETO..., 2016).

Sabe-se que, no entanto, a aplicação rigorosa da Lei em nada modifica a compreensão dos cidadãos, pois não se atinge a origem do problema, como reflete a advogada Maíra Fernandes, integrante do Comitê Latino Americano de Defesa dos Direitos da Mulher:

[...] Aumentar pena não é solução para acabar com crime, nunca foi e nunca será. Estupro já tem uma das maiores penas no Código Penal, e mesmo assim é um crime que acontece aos montes. Na verdade, a única forma de resolver esse problema é mudar a mentalidade dos homens através da educação, para que, efetivamente, não cometam mais estupros. Só através da educação, da discussão sobre feminismo e gênero nas escolas, universidades e em todos os locais, que vamos conseguir evitar os estupros (PUTTI, 2016).

Como visto, aumentar a pena não é a solução e, para melhor combater a problemática, contestam-se os argumentos mais utilizados: se o estupro de fato se tratasse sobre a roupa que a vítima vestia no momento do crime, as ocorrências teriam considerável aumento no verão, o que, entretanto, não acontece; de acordo com o Instituto de Pesquisa Econômica Aplicada, os estupros acontecem mais no inverno (2014a, p. 13). Os estupros, como já visto, ocorrem desde os tempos imemoriais e, portanto, existiam muito antes do surgimento de uma minissaia, por exemplo. Se o estupro versasse acerca da conduta sexual anterior da vítima, as crianças não seriam estupradas, mas elas são e figuram como $70 \%$ das vítimas (INSTITUTO DE PESQUISA ECONÔMICA APLICADA, 2014a, p. 7).

Os demais comentários discriminatórios emanados pelo 
seio social "se estivesse estudando não seria estuprada", "se ela estivesse na Igreja não seria estuprada", "se ela possuísse namorado fixo não seria violentada", e muitos outros que surgem diante o relato de um estupro, também não prestam compromisso com a realidade e não podem ser mais propagados. Isso porque mesmo nas circunstâncias acima citadas os estupros ocorrem, como se viu quando uma menina foi estuprada dentro de uma escola em São Paulo (G1 SÃO PAULO), quando outra foi estuprada durante a missa, dentro do banheiro da Igreja (VARELA NOTÍCIAS) ou quando uma mulher foi estuprada por um ano pelo próprio namorado enquanto dormia (ROSNEY, 2016).

Haverá sempre uma justificativa para a violência, mas os estupros ocorrem em qualquer lugar, âmbito e condição, pois independem da conduta da vítima. Eles tendem a ser, na realidade, perpetrados por pessoas do ciclo social, e quando o agressor é conhecido, 65\% dos estupros de adultos ocorrem dentro da própria residência, índice que chega a 79\% quando a vítima é criança (INSTITUTO DE PESQUISA ECONÔMICA APLICADA, 2014a, p. 12).

O estupro é, portanto, causado pelos estupradores, pela misoginia, pela violência estruturada na sociedade, pela desigualdade de gênero e pela tolerância institucional. É causado por uma mentalidade machista e discriminatória da mulher, não possuindo, pois, qualquer relação com a atitude moral ou conduta da vítima. Sabe-se que toda mulher possui em si uma característica que pode ser utilizada para culpabilizá-la, qual seja, o fato de ser mulher; e nenhuma merece ser estuprada por essa razão e, tampouco, culpabilizada quando da ocorrência da violência.

O que se deve proceder, dessa forma, é a educação da orla masculina, recorrendo-se a novos caminhos, contrários, in casu, à aplicação rigorosa da Lei, que em nada modifica a cul- 
tura do estupro e o culto à violência e discriminação da mulher (PUTTI, 2016). Deve-se implementar um novo molde de educação, readequando a ética e moral dos indivíduos, para que não tratem mais a mulher como objeto de consumo e para que não a coloquem em patamar de submissão.

\section{CONCLUSÃ̃o}

Em face das situações analisadas, conclui-se que a cultura de estupro se encontra imersa em um arcabouço moral e social, sendo necessário para a modificação desse cenário mudança profunda no tratamento da mulher perante a sociedade. É, portanto, imperiosa a implementação de reciprocidade societária, visando, a priori, eliminar a desigualdade de gênero, admitindo-se a liberdade de escolha, de locomoção, bem como a liberdade sexual da mulher; por hora, ainda abstrusa e limitada.

Para que isso seja vislumbrado, se demonstra fundamental a readequação de premissas e maior comprometimento dos ordenadores do direito para com os direitos da mulher, a fim de se obter a sua real emancipação. Imprescindível a implementação de políticas não discriminatórias, recorrendo-se à educação dos cidadãos, para melhor instruí-los acerca do gênero, da disparidade proveniente deste ainda vigente, do movimento feminista, e da longa jornada a ser percorrida em busca da visibilidade, do reconhecimento e da inserção da mulher em seu devido lugar, aquele em que esta desejar estar.

\section{REFERÊNCIAS}

ANDRADE, Vera Regina de. A soberania patriarcal: o sistema de justiça criminal no tratamento da violência sexual contra a mulher. Revista Sequência: Florianópolis, v. 26, n. 50, p. 71-102, jul. 2005. Disponível em: $<$ https://periodicos.ufsc.br/index.php/ sequencia/article/view/15185/13811>. Acesso em: 28 jul. 2016.

BIANCHI, Paula. “Crime está provado”, diz delegada que investiga estupro coletivo no Rio. Disponível em: <http://noticias.uol.com.br/cotidiano/ultimas-noticias/2016/05/30/ crime-esta-provado-diz-delegada-que-investiga-estupro-coletivo-no-rio.htm $>$. Acesso 
em: 31 jul. 2016.

BICALHO, Renata de Almeida; DE PAULA, Ana Paula Paes.Violência Simbólica: uma Leitura a partir da Teoria Crítica Frankfurtiana. Encontro de Gestão de Pessoas e Relações de Trabalho: Curitiba, 3, 2009. Disponívelem:<http://www.anpad.org.br/diversos/ trabalhos/EnGPR/engpr_2009/2009_ENGPR137.pdf>. Acessoem: 27 jul. 2016.

BRASIL. Lei $n^{\circ} 12.015$, de 7 de agosto de 2009. Altera o Título VI da Parte Especial do Decreto-Lei no 2.848, de 7 de dezembro de 1940-Código Penal, e o art. $1^{\circ}$ da Lei no 8.072, de 25 de julho de 1990, que dispõe sobre os crimes hediondos, nos termos do inciso XLIII do art. $5^{\circ}$ da Constituição Federal e revoga a Lei no 2.252, de 1o de julho de 1954, que trata de corrupção de menores. Disponível em: $<$ http://www.planalto.gov. br/ccivil_03/_Ato2007-2010/2009/Lei/L12015.htm\#art2>. Acessoem: 31 jul. 2016.

BROWNMILLER, Susan. AgainstOur Will: men, womenand rape. New York: Ballantine Books, 1993.

BUENO, Samira. A Índia é aqui. Anuário Brasileiro de Segurança Pública 2015, São Paulo, ano 9, p. 116, 2015.. Disponível em: $<$ http://www.forumseguranca.org.br/storage/download/anuario_2015.retificado_.pdf>. Acesso em: 27 jul. 2016.

CANADIAN RESOURCE CENTRE FOR VICTIMS OF CRIME. VictimBlaming. Disponível em: <http://crcvc.ca/docs/victim_blaming.pdf $>$. Acesso em: 30 jul. 2016.

CRUZ, Sabrina Uzêdada. A representação da mulher na mídia: um olhar feminista sobre as propagandas de cerveja. In: ENCONTRO DE ESTUDOS MULTIDISCIPLINARES EM CULTURA, 4., 2008, Salvador. Anais eletrônicos... Disponível em: $<$ http://www.cult.ufba.br/enecult2008/14477.pdf>. Acesso em: 29 jul. 2016.

DALARUN, Jacques. Olhares de clérigos. In: DUBY, Georges; PERROT, Michelle. (Orgs.) História das Mulheres no Ocidente: A Idade Média. 476. ed. Porto: Edições Afrontamento, 1993. p. 29-63. v. 2.

DELMANTO, C. et al. Código penal comentado: acompanhado de comentários, jurisprudência, súmulas em matéria penal e legislação complementar. 8. ed. rev., atual. eampl. São Paulo: Saraiva, 2010.

DIAS, Maria Berenice. Lei Maria da Penha - sentimento e resistência à violência doméstica. 30 ago. 2010. Disponível em: $<$ http://www.mariaberenice.com.br/manager/ $\operatorname{arq} /(\operatorname{cod} 2$ _817)21_lei_maria_da_penha_sentimento_e_resistencia_a_violencia_ domestica.pdf>. Acesso em: 30 jul. 2016.

EDWARDS, Sarah R., BRADSHAW, Kathryn A., HINSZ, Verlin B. Denying Rape but Endorsing Forceful Intercourse: Exploring Differences Among Responders. Mary Ann Liebert Inc. Publishers: Violence and Gender, North Dakota, v. 1, n. 4, p. 188-193, 2014. Disponível em: <http://online.liebertpub.com/doi/pdf/10.1089/vio.2014.0022>. Acesso em: 21 maio 2016.

FLETCHER, Pamela R. Dismantling Rape Culture around the World: A Social Justice Imperative. Forumon Public Policy: Minnesota, v. 2010, n. 4, p. 1-14, dez. 2010. Disponível em: $<$ http://forumonpublicpolicy.com/vol2010.no4/archive.vol2010.no4/ fletcher.pdf $>$. Acesso em: 29 jul. 2016.

GASMAN, Nadine. Nota pública da ONU Mulheres Brasil sobre estupros coletivos. In: ORGANIZAÇÃO MUNDIAL DA SAÚDE MULHERES BRASIL, 26 maio 2016. Disponível em: $<$ http://www.onumulheres.org.br/noticias/nota-publica-da-onu- 
mulheres-brasil-sobre-estupros-coletivos/.>. Acesso em: 31 jul. 2016.

GRECO, Alessandra Orcesi Pedro. A autocolocação da vítima em risco. São Paulo: Editora Revista dos Tribunais, 2004. v. 7.

G1 SÃO PAULO. Menina estuprada em escola de SP reconhece agressores, diz advogada. Disponível em: $<$ http://g1.globo.com/sao-paulo/noticia/2015/05/menina-estupradaem-escola-de-sp-reconhece-agressores-diz-advogada.html>. Acesso em: 30 jul. 2016.

INSTITUTO AVON. Violência contra a mulher no ambiente universitário. Disponível em: <http://agenciapatriciagalvao.org.br/wp-content/uploads/2015/12/PesquisaInstituto-Avon_V9_FINAL_Bx.pdf>.Acesso em: 30 jul. 2016.

INSTITUTO DE PESQUISA EM ECONÔMICAAPLICADA. Estupro no Brasil: uma radiografia segundo os dados da Saúde (versão preliminar). Brasília, 2014a. Disponível em: <http://www.ipea.gov.br/portal/images/stories/PDFs/nota_tecnica/140327 notatecnicadiest11.pdf $>$. Acesso em: 28 jul. 2016.

. Tolerância social à violência contra as mulheres. Brasília, 2014b. Disponível em: $<$ http://www.ipea.gov.br/portal/images/stories/PDFs/SIPS/140327_sips violencia_mulheres_novo.pdf $>$. Acesso em: 30 jul. 2016.

IZUMINO, WâniaPasinato. Justiça e violência contra a mulher: o papel do sistema judiciário na solução dos conflitos de gênero. 2. ed. São Paulo: Annablume: FAPESP, 2004.

LANA, B. et al. $\neq$ MeuAmigoSecreto: feminismo além das redes. Rio de Janeiro: Edições de Janeiro, 2016.

LIBERO, Daiane. Gentili apaga postagem em que chama de gênio quem transa com mulher bêbada. Disponível em: $<$ http://www.midiamax.com.br/famosos/gentili-apagapostagem-chama-genio-quem-transa-bebada-302468>. Acesso em: 30 jul. 2016.

LIMA, Marina Torres Costa. O estupro enquanto crime de gênero e suas implicações na prática jurídica, do Curso de Direito da UEPB - Campus de Campina Grande. 2012. 34 f. Monografia (Graduação em Direito)-Universidade Estadual da Paraíba, Campina Grande, 2012. Disponível em:<http://dspace.bc.uepb.edu.br/jspui/ bitstream/123456789/5370/1/PDF\%20-\%20Marina\%20Torres\%20Costa\%20Lima. pdf>. Acesso em: 30 jul. 2016.

MARREIRO, Flávia. Advogada de garota carioca: "Vou pedir a saída do delegado do caso". Disponível em: $<$ http://brasil.elpais.com/brasil/2016/05/28/ politica/1464442969_569756.html>. Acesso em: 31 jul. 2016.

NASCIMENTO, Marcos. Estereótipos de gênero e violência. In: INSTITUTO AVON. Percepções dos homens sobre a violência doméstica contra a mulher: Instituto Avon, 2013. p. 26-31. Disponível em: $<$ http://centralmulheres.com.br/data/avon/PesquisaAvon-Datapopular-2013.pdf>. Acesso em: 30 jul. 2016.

NASCIMENTO, Silvana de Souza. Cultura do estupro é o apogeu da (falida) dominação masculina. Disponível em: $<$ http://jornal.usp.br/artigos/cultura-do-estupro-e-oapogeu-da-falida-dominacao-masculina/>. Acesso em: 06 jul. 2016.

ORDEM DOS ADVOGADOS DO BRASIL. Deputado é denunciado por incitação ao estupro. Disponível em: <http://www.oab.org.br/noticia/27949/deputado-edenunciado-por-incitacao-ao-estupro $>$. Acesso em: 30 jul. 2016. 
PIMENTEL, Silvia; SCHRITZMEYER, Ana Lúcia Pastore; PANDJIARJIAN, Valéria. Estupro, crime ou "cortesia”, uma abordagem sociojurídica de gênero. Porto Alegre: Sergio Antonio Fabris Editor, 1998.

PONTE JORNALISMO. Policiais expõem e ridicularizam adolescente vítima de estupro. Disponível em: $<$ http://ponte.org/adolescente-estuprada-exposta/ $>$. Acesso em: 31 jul. 2016.

POSADA, Dario Adolfo Córdova. Estereótipos de gênero e violência. In: Percepções dos homens sobre a violência doméstica contra a mulher. Instituto Avon, 2013. p. 18-25. Disponível em: $<$ http://centralmulheres.com.br/data/avon/Pesquisa-AvonDatapopular-2013.pdf $>$. Acesso em: 30 jul. 2016.

PRAGMATISMO POLÍTICO. Alexandre Frota confessa um crime em rede nacional. Disponível em: <http:/www.pragmatismopolitico.com.br/2015/03/alexandre-frotaconfessa-um-crime-em-rede-nacional.html>. Acesso em: 30 jul. 2016.

PROJETO aumenta penas e condiciona a liberdade de estuprador à castração química. Disponível em: $<$ http://www2.camara.leg.br/camaranoticias/noticias/ SEGURANCA/457424-PROJETO-AUMENTA-PENAS-E-CONDICIONALIBERDADE-DE-ESTUPRADOR-A-CASTRACAO-QUIMICA.html>. Acesso em: 28 jul. 2016.

PROJETO que aumenta a pena para estupro coletivo pode entrar na pauta do Plenário. Agência Senado, 31 maio 2016. Disponível em: $<$ http://www12.senado.leg.br/noticias/ materias/2016/05/31/projeto-que-aumenta-a-pena-para-estupro-coletivo-pode-entrarna-pauta-do-plenario $>$. Acesso em: 31 jul. 2016.

PUTTI, Alexandre. "Aumentar pena não é solução para acabar com estupro, nunca foi e nunca será", afirma especialista. Justificando. Disponível em: $<$ http://justificando. com/2016/06/03/aumentar-pena-nao-e-solucao-para-acabar-com-estupro-nunca-foi-enunca-sera-afirma-especialista/>. Acesso em: 30 jul. 2016.

R7 ENTRETENIMENTO. Rafinha Bastos faz piada de mau gosto sobre estupro. Disponível em: $<$ http://entretenimento.r7.com/famosos-e-tv/noticias/rafinha-bastos-fazpiada-de-mau-gosto-sobre-estupro-20110508.html >. Acesso em: 30 jul. 2016.

ROSNEY, Daniel. "Meu namorado me estuprou por um ano enquanto eu dormia". Disponível em: <http://www.bbc.com/portuguese/noticias/2015/12/151209_relato_ vitima_estupro_namorado_sono_lgb $>$. Acesso em: 30 jul. 2016.

ROST, Mariana; VIEIRA, Miriam Steffen. Convenções de Gênero e Violência Sexual: A cultura de estupro no ciberespaço. Contemporânea: Revista de Comunicação e Cultura, Bahia, v. 13, n. 2, p. 261-276, maio./ago. 2015. Disponível em: <http://www. portalseer.ufba.br/index.php/contemporaneaposcom/article/view/13881/9878>. Acesso em: 30 jul. 2016.

SAKAMOTO, Leonardo. Cultura do estupro no Brasil: homem, de que lado você está? Disponível em: $<$ http://blogdosakamoto.blogosfera.uol.com.br/2016/05/26/cultura-doestupro-no-brasil-homem-de-que-lado-voce-esta/>. Acesso em: 30 jul. 2016.

SANTOS, Lígia Pereira dos. Mulher e violência: histórias do corpo negado. Campina Grande: EDUEP, 2008.

SEMÍRAMIS, Cynthia. Sobre a cultura do estupro. Revista Fórum. Disponível em:<http://www.revistaforum.com.br/2013/04/16/cultura-do-estupro/>. Acesso em: 
30 jul. 2016.

SILVA, Luciana Santos. O que queres tu mulher? Manifestações de gênero no debate da constitucionalidade da "Lei Maria da Penha". In: $5^{\circ}$ PRÊMIO Construindo a igualdade de gênero - redações, artigos científicos e projetos pedagógicos premiados. 5.ed. Brasília: Presidência da República, Secretaria de políticas públicas para as mulheres, 2010. p. 48-68.

SILVA, Natiene Ramos Ferreira da. Representações da culpabilização das mulheres vítimas de estupro: uma análise étnico-racial. In: BRASIL. $9^{\circ}$ PREMIO Construindo a Igualdade de Gênero - Redações, artigos científicos e projetos pedagógicos premiados: Brasília, p. 133-147, 2014. Disponível em: $<$ http://estatico.cnpq.br/portal/ premios/2014/ig/pdf/spm_9premio_web.pdf.>. Acesso em: 23 abr. 2016.

SCHOELLKOPF, Julia Churcill. Victim-Blaming: A New Term for na Old Trend. Digital Comons: Lesbian Gay Bissexual TransgenderQueer Center, RhodeIsland, $\mathrm{n}^{\circ} 33$, p. 1-14, 2012. Disponível em: < http://digitalcommons.uri.edu/cgi/viewcontent.cgi?arti cle $=1032 \&$ context $=$ glbtc $>$. Acesso em: 30 jul. 2016.

SMINKLEY, Laura. WHO urges Governments to take action to reduce violence against women. Disponível em:<http://www.who.int/mediacentre/news/releases/pr89/ en/>. Acesso em: 06 jul. 2016.

SOUTHERN CONNECTICUT STATE UNIVERSITY. Rape Culture, Victim Blaming, and the facts. Disponível em: <https://www.southernct.edu/sexual-misconduct/ facts.html>. Acesso em: 30 jul. 2016.

SOUZA, José Guilherme de. Vitimologia e violência nos crimes sexuais: uma abordagem interdisciplinar. Porto Alegre: Sergio Antonio Fabris Editor, 1998.

VARELA NOTÍCIAS. Menina de 13 anos é estuprada em banheiro de igreja durante missa. Disponível em: <http://varelanoticias.com.br/menina-de-13-anos-e-estupradaem-banheiro-de-igreja-durante-missa/>. Acesso em: 30 jul. 2016.

WHAT isobjetification? Disponível em: <http://womennotobjects.com/what-isobjectification/>. Acesso em: 29 jul. 2016.

WOMENS AGAINST VIOLENCE AGAINST WOMEN. What is pape culture? Disponível em:<http://www.wavaw.ca/what-is-rape-culture/>. Acesso em: 30 jul. 2016.

WOMEN'S CENTER OF MARSHALL UNIVERSITY. Rape culture. Disponível em:<https://www.marshall.edu/wcenter/sexual-assault/rape-culture/>. Acesso em: 29 jul. 2016.

Artigo recebido em: 16/06/2017

Artigo aprovado em: 10/10/2017 